\title{
Intrahepatic metastases may be specific to hepatocellular carcinoma due to the coagulation and fibrinolytic systems (Review)
}

\author{
XUEMEI LI ${ }^{1 *}$, BAOHONG GU $^{1 *}$, BOFANG WANG ${ }^{1}$, ZEDONG FENG $^{1}$, YANLING MA ${ }^{1}$, \\ HAIYUAN LI ${ }^{1}$, ALEXANDRA LUCAS ${ }^{2}$ and HAO CHEN ${ }^{3,4}$ \\ ${ }^{1}$ The Second Clinical Medical College of Lanzhou University, Lanzhou, Gansu 730000, P.R. China; \\ ${ }^{2}$ Biodesign Institute, Arizona State University, Tempe, AZ 85287, USA; ${ }^{3}$ Department of Tumor Surgery, and \\ ${ }^{4}$ The Key Laboratory of the Digestive System Tumors of Gansu Province, Lanzhou University Second Hospital, \\ Lanzhou, Gansu 730000, P.R. China
}

Received June 11, 2020; Accepted September 23, 2020

DOI: $10.3892 / o r .2020 .7800$

\begin{abstract}
Hepatocellular carcinoma (HCC) is different from other solid tumors because it is commonly associated with the occurrence of intrahepatic metastasis. Additionally, the liver, unlike other organs, is the main site of coagulation and fibrinolytic factor production. Therefore, it was speculated that coagulation and fibrinolytic factors could be associated with intrahepatic metastasis of HCC. Do the coagulation and fibrinolytic systems protect $\mathrm{HCC}$ cells against anoikis during infiltration and metastasis? Conversely, do the coagulation and fibrinolytic systems lead to immune escape of HCC cells by affecting the immune microenvironment of patients? The current review aimed to present a number of novel hypotheses for the treatment of HCC by exploring the mechanisms of coagulation and fibrinolytic factors in the regulation of cancer growth.
\end{abstract}

\section{Contents}

1. Introduction

2. Coagulation characteristics of cancer

3. Regulation of the coagulation and fibrinolytic systems in HCC

Correspondence to: Dr Hao Chen, Department of Tumor Surgery, Lanzhou University Second Hospital, Lanzhou, Gansu 730000, P.R. China

E-mail: ery_chenh@1zu.edu.cn

Dr Alexandra Lucas, Biodesign Institute, Arizona State University, Tempe, AZ 85287, USA

E-mail: arlucas5@asu.edu

*Contributed equally

Key words: hepatocellular carcinoma, intrahepatic metastasis, coagulation-fibrinolytic system, anti-anoikis, immune escape
4. Role of the coagulation system in resistance of HCC cells to anoikis

5. uPA system and immunotherapy for HCC

6. Summary and outlook

\section{Introduction}

Hepatocellular carcinoma (HCC) is becoming a critical malignancy affecting human health worldwide $(1,2)$. The 5-year survival rate of patients with HCC is $<12 \%(3,4)$. Although surgical resection is the common therapeutic approach for patients with HCC at an early stage, recurrence is observed in $>70 \%$ of patients within 5 years (5). Local metastasis and chemoresistance remain the key causes of the poor prognosis of HCC (6).

It has been established that the coagulation and fibrinolytic systems serve important roles in the human body by maintaining the balance of the physiological coagulation process, which is closely associated with liver functions, including generation of clotting factors, and synthesis of fibrinolytic and antifibrinolytic substances (7). However, recent studies have indicated that both systems can also influence the development and prognosis of HCC $(8,9)$. It has been demonstrated that elevated levels of serum urokinase plasminogen activator (uPA) are associated with higher mortality of patients with HCC after resection (8). The clinical course of certain tumor types can be slowed down by protease inhibitors, which inhibit uPA expression (9). Similarly, the majority of patients with cancer exhibit some changes in the coagulation and fibrinolytic systems $(10,11)$. However, it is unclear whether these changes have any effects on the biological behavior of cancers and how they interact with each other.

\section{Coagulation characteristics of cancer}

The blood coagulation and fibrinolytic systems are mainly involved in maintaining a balance between thrombogenesis and bleeding, and in keeping blood vessels unobstructed. However, systemic activation of blood coagulation is also a prominent 
characteristic of cancer, and various coagulation components have been identified to be associated with malignant phenotypes (10). For example, high fibrinogen expression has been suggested to contribute to the poor prognosis of patients with advanced cancer (11).

Coagulation activation in cancer can be classified into two types: Non-specific and tumor cell-specific (Fig. 1). The causes of non-specific activation include damaged tissues, inflammation, surgery, chemotherapy drugs and radiation. The causes of tumor cell-specific activation can be 'direct' or 'indirect'. For example, tissue factor (TF), which is expressed by tumor cells, can trigger coagulation directly. Furthermore, certain cytokines, which are expressed by tumor cells, may activate procoagulant expression of endothelial cells, which can trigger coagulation indirectly. Patients with tumors can be divided into three groups according to specific coagulation activation. Certain patients exhibit generation of thrombin and fibrin by tumor cells but minor systemic coagulation activation, and these patients belong to the direct activation group (12). Other patients exhibit marked and deadly coagulation activation but small tumor tissues, and these patients belong to the indirect activation group (13). The remaining patients who do not belong to either of these groups may exhibit only limited activation of coagulation (14).

Animal models suggest that numerous drugs that regulate coagulation activities also have antitumor effects $(15,16)$. These drugs can attenuate tumor growth, decrease metastasis and prolong survival time. Furthermore, the majority of the components associated with coagulation and fibrinolysis contribute to HCC in some way (Table I).

\section{Regulation of the coagulation and fibrinolytic systems in $\mathrm{HCC}$}

Clotting factors and HCC. Coagulation factor VII (FVII) combines with TF to initiate the exogenous coagulation signaling pathway, which activates the coagulation cascade and platelets (17). Upregulation of TF has been identified in numerous types of cancer, including HCC. Zhou et al (18) demonstrated that both plasma and tissue samples from patients with HCC exhibited high levels of TF, and this promoted invasion and metastasis via regulation of the AKT/ ERK-EGFR signaling pathway (19). Mouse models and clinical follow-up revealed that TF expression is associated with angiogenesis and invasiveness of HCC $(20,21)$. The plasma levels of TF in patients with HCC are associated with the degree of tumor differentiation, tumor size and occurrence of hepatic cirrhosis (22).

Hepatic metastasis of colorectal cancer (CRC) is closely associated with TF expression, and TF knockdown inhibits hepatic metastasis in vitro and in vivo via activation of apoptosis and autophagy $(23,24)$. Furthermore, a TF-FVIIa inhibitor (FFRFVIIa) was found to be able to attenuate hepatic metastasis of CRC (25). Neaud et al (26) revealed that TF pathway inhibitor-2 could induce invasion of HCC cells following binding to the TF-FVIIa complex, and this could be inhibited in a dose-dependent manner by an antibody against human factor VII.

FVII/proteinase-activated receptor 2 (PAR2) promotes migration of HCC cells via activation of the MEK/ERK,
TSC complex subunit 2 and mTOR signaling pathways (27). Additionally, Chen et al (28) demonstrated that TF, FVII and PAR2 increased the invasion and migration of HCC cells via mTOR signaling to inhibit autophagy. Furthermore, Lin et al indicated that the four common polymorphisms in the promoter region of the FVII gene $(-122 \mathrm{~T} / \mathrm{C},-323$ ins $10-\mathrm{bp},-401 \mathrm{G} / \mathrm{T}$ and $-402 \mathrm{G} / \mathrm{A}$ ) had no effects on the incidence, survival and recurrence in patients with HCC (29).

Coagulation factors VIII (FVIII) and XII (FXII) may also contribute to HCC to some extent. Dihydrodiosgenin was found to inhibit the lung metastasis of mouse HCC cells by decreasing FVIII secretion via the PI3K, MAPK and NF- $\mathrm{KB}$ signaling pathways, and this led to anoikis of HCC cells $(30,31)$. Astrocyte elevated gene-1 induced marked upregulation of FXII levels, and increased angiogenesis and progression of HCC $(32,33)$.

uPA system and HCC. UPA, uPA receptor (uPAR), and plasminogen activator inhibitor (PAI)-1 and PAI-2, are four components of the uPA system. All of them may contribute to the metastasis of HCC.

Plasminogen can be converted to plasmin by uPA, and promotes angiogenesis and tumor growth, degrading the extracellular matrix (ECM) and activating pro-MMPs (34). Matrix metalloproteinases (MMPs), particularly MMP-2 and MMP-9, are able to degrade type IV collagen (an ECM component) to promote invasion and metastasis of cancer (35). Previous studies have demonstrated that uPA could activate MMP-2/MMP-9 to enhance the invasion and migration of $\operatorname{HCC}(36,37)$.

Higher expression levels of uPA have been observed in aggressive HCC cells compared with levels in HCC cells with low levels of invasiveness (9). Patients with HCC, particularly those with a portal tumor embolus and metastasis, also exhibit high levels of uPA and uPAR. The positive rates of UPA and UPAR in patients with HCC were found to be 72 and $86 \%$, respectively, and a positive rate of UPAR of $100 \%$ was observed in patients who died within 2 years after surgery (8). Phosphorylation of ERK1/2 and PI3K/Akt, and activation of the protein tyrosine kinase 2 (FAK), NF- $\kappa$ B and STAT3 signaling pathways may contribute to these processes $(38,39)$. Hepatocyte growth factor (HGF) was demonstrated to promote the invasion of HCC cells by enhancing the levels of UPA and uPAR. Monoclonal antibodies against UPAR were found to inhibit tumor cell invasion mediated by HGF in a dose-dependent manner (40). Bicyclol inhibited the invasiveness of HCC cells by decreasing the expression levels of uPAR (41). A novel inhibitor of uPA, serine peptidase inhibitor Kazal type 13, also inhibited intrahepatic metastasis of HCC in vivo (9).

PAI-1 and PAI-2 are regulators of UPA and UPAR involved in activating plasminogen, initiating signal transduction and inducting cell chemotaxis (42). High PAI-1 levels in tumors are associated with poor prognosis; however, the PAI-2 level may be associated with a beneficial prognosis $(43,44)$. In a Taiwanese population, PAI-1 genotypes were considered as a critical factor which led to higher susceptibility and pathological development in patients with HCC (45). Furthermore, patients with CRC with liver metastasis were demonstrated to have higher plasma levels of PAI-1, and the levels were associated with tumor differentiation, tumor size, Duke's 


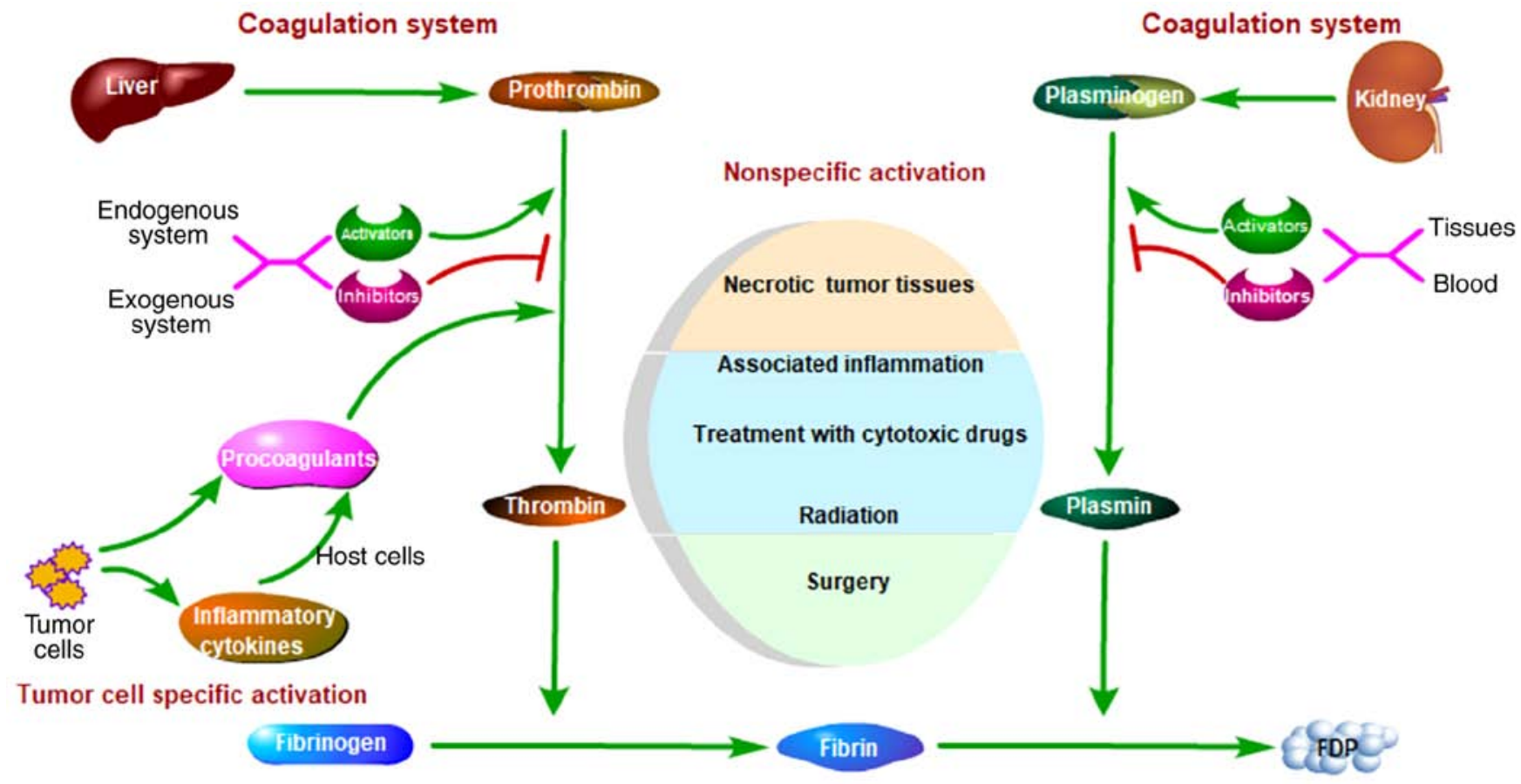

Figure 1. Coagulation characteristics of cancer. Usually, the blood coagulation system and the fibrinolytic system are important physiological activities maintaining the balance between thrombogenesis and bleeding. However, systemic activation of the blood coagulation mechanism is also a prominent characteristic of cancer, which may be non-specific or tumor cell-specific.

stage and lymphatic metastasis (46). Elevated plasma levels of PAI-1 have been suggested to be a predictor of unfavorable prognosis in patients with $\mathrm{HCC}$ with serpin family $\mathrm{E}$ member $14 \mathrm{G} / 4 \mathrm{G}$ polymorphism undergoing transarterial chemoembolization (47).

Other studies have made opposite observations regarding the effects of PAI-1 on HCC. Wang et al (48) revealed that berberine could trigger cell apoptosis by generating reactive oxygen species, and could inhibit the migration and invasion of HCC cells. This may be associated with the upregulation of PAI-1, which could decrease the expression levels of cyclooxygenase-2 (Cox-2), NF- $\mathrm{kB}$, uPA and uPAR via inactivation of the $\mathrm{p} 38$ and ERK1/2 signaling pathways (48).

There is limited research on PAI-2 in HCC. PAI-2 was found to inhibit invasion of HCC MHCC97-H cells via uPAand retinoblastoma/transcription factor E2F1-associated mechanisms (49).

Des- $\gamma$-carboxy prothrombin (DCP) and HCC. DCP is produced in HCC cells in the absence of vitamin K or the presence of vitamin $\mathrm{K}$ antagonists, and may stimulate growth, invasion and metastasis of HCC. Previous research has indicated that $44-81 \%$ of patients with HCC exhibit elevated serum levels of DCP (50). DCP is widely used as a serologic tumor marker for the diagnosis and follow-up of HCC (51). Although its sensitivity is lower than that of $\alpha$-fetoprotein (AFP), it has a higher specificity than AFP. A number of studies have suggested that higher levels of DCP may be associated with poor tumor behavior and prognosis of patients with HCC $(52,53)$. Additionally, positive serum DCP expression is closely associated with vascular invasion, intrahepatic metastasis, TNM stage and recurrence in patients with HCC (54).
DCP induces the proliferation of HCC cells via activation of the MET proto-oncogene receptor tyrosine kinase (Met)-Jak family tyrosine kinases-STAT signaling pathway (55). Furthermore, binding of DCP to c-Met can activate various downstream effectors, such as autophosphorylation of EGFR, to increase the proliferation and angiogenesis of HCC (56). Yue et al (57) suggested that DCP could increase the activity of MMP-2/MMP-29 via activation of the ERK1/2-MAPK signaling pathway to promote the growth and metastasis of HCC.

It is crucial for DCP generation to decrease vitamin K uptake through cytoskeletal changes in the process of epithelial-to-fibroblastoid conversion induction by chemical methods (58). Hypoxia can induce the production of DCP in HCC cells in this way (59). Vitamin K2 can inhibit the generation of DCP, and DCP levels can also be decreased by vitamin $\mathrm{K} 2$ analogues in patients with $\mathrm{HCC}(60,61)$.

Other factors and HCC. In addition to the aforementioned components of the coagulation and fibrinolytic systems, there are other factors that also contribute to $\mathrm{HCC}$ to a certain extent.

Thrombomodulin (TM) acts as a natural anticoagulant factor and is present at high levels in endothelial cells to maintain unobstructed circulation. TM has been demonstrated to serve roles in inflammation, thrombosis and carcinogenesis (62). A study of TM in 141 patients with HCC who underwent surgery suggested that TM may inhibit tumor cell invasion to the portal vein and prevent intrahepatic metastasis (63). Furthermore, silencing of TM expression markedly increased the migration of HCC cells by decreasing E-cadherin levels and increasing zinc finger E-box binding homeobox 1 (ZEB1) levels (64). 
Table I. A list of studies on the relationship between the coagulation system and HCC.

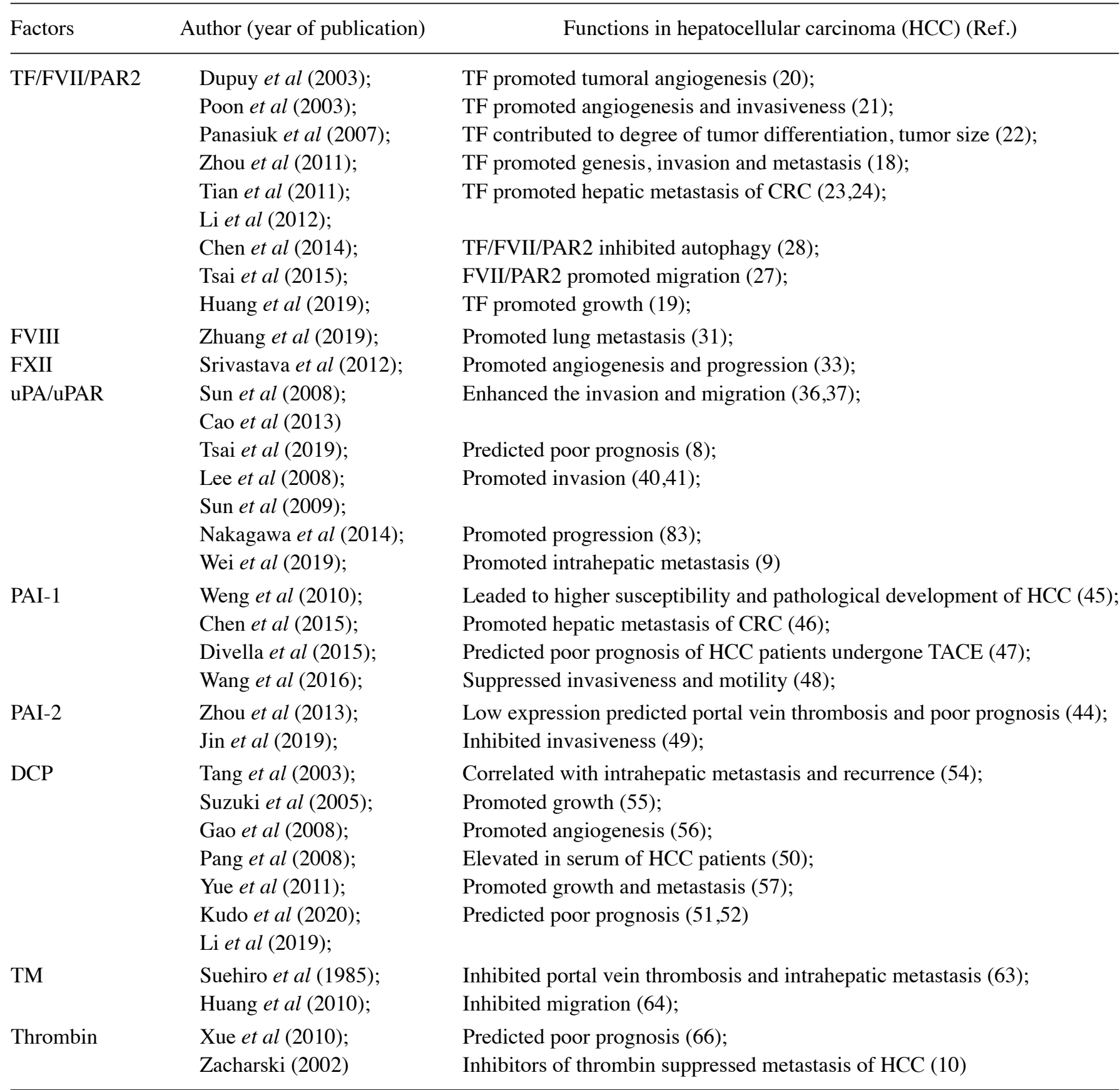

TF, tissue factor; FVII, coagulation factor VII; FVIII, coagulation factor VIII; FXII, coagulation factor XII; uPA, urokinase plasminogen activator; uPAR, urokinase plasminogen activator receptor; PAR2, proteinase-activated receptor 2; CRC, colorectal cancer; PAI, plasminogen activator inhibitor; TACE, transcatheter arterial chemoembolization; TM, thrombomodulin; DCP, Des- $\gamma$-carboxy prothrombin.

Thrombin is a serine protease and serves multiple roles in coagulation. A previous study revealed that thrombin could induce changes in osteopontin (OPN) activity (a potential therapeutic target for inhibiting HCC metastasis) (65). Furthermore, another study demonstrated that these changes served a key role in the aggressive phenotype of HCC mediated by OPN via activation of integrin $\beta 1-\mathrm{FAK}$, and thrombin was associated with poor prognosis in HCC (66). Several thrombin inhibitors available for clinical treatment, including non-specific anticoagulants and thrombin-specific inhibitors, have been demonstrated to inhibit metastasis in experimental models (10).

\section{Role of the coagulation system in resistance of $\mathrm{HCC}$ cells to anoikis}

Anoikis is critical to ensure that cells contact the ECM appropriately and to limit the invasiveness of cancer. However, numerous cancer cells can survive by suppressing anoikis to stimulate tissue invasion and to confer metastatic abilities to cancer cells (67). Resistance to anoikis is a prerequisite for the metastasis of epithelial cancer cells $(68,69)$. As a typical malignant tumor derived from epithelial cells, HCC obtains the ability of anoikis resistance to survive in the bloodstream, 


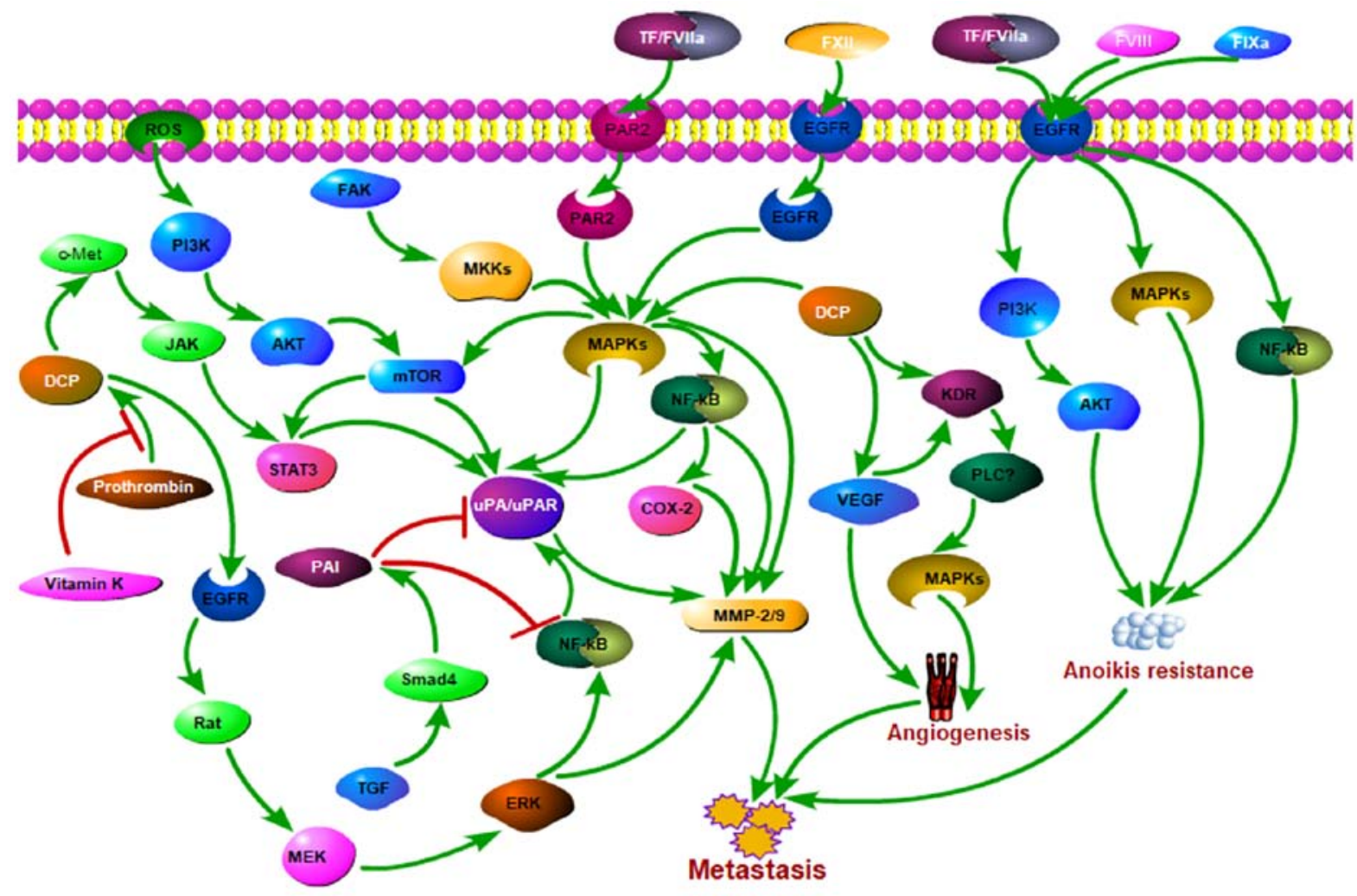

Figure 2. Signaling pathways of the coagulation and fibrinolytic systems contribute to HCC. The majority of the components associated with the coagulation and fibrinolytic systems contribute to HCC via certain signaling pathways. These signaling pathways are not biologically divided. Indeed, they are connected to each other, and are associated with angiogenesis, anoikis resistance and metastasis of HCC cells. HCC, hepatocellular carcinoma; TF, tissue factor; FVIIa, coagulations factor VIIa; FXII, coagulation factor XII; FVIII, coagulation factor VIII; FIXa, coagulation factor IXa; PAR2, proteinase-activated receptor 2; EGFR, epithelial growth factor receptor; uPAR, urokinase plasminogen activator receptor; DCP, Des- $\gamma$-carboxy prothrombin; COX-2, cyclooxygenase-2; ROS, reactive oxygen species; PAI, plasminogen activator inhibitor; MMP, matrix metalloproteinase; STAT3, signal transducer and activator of transcription 3; VEGF, vascular endothelial growth factor; mTOR, mammalian target of rapamycin; TGF, transforming growth factor; PI3K, phosphatidylinositol 3-kinase; MAPKs, mitogen-activated protein kinases; PLC $\gamma$, Phospholipase C- $\gamma ;$ KDR, kinase domain region receptor; NF- $\mathrm{B}$, nuclear factor-kappaB.

and to subsequently metastasize and become more resistant to anticancer agents (70).

Various coagulation components may be involved in the anoikis resistance of HCC. Cellular communication network factor 3 downstream genes TF and thrombin, which are positively associated with the malignant phenotype of HCC and vascular thrombosis, prolong survival time and improve pulmonary metastasis in vivo. Mechanistically, ERK and $\mathrm{NF}-\kappa \mathrm{B}$ signaling are activated in order to maintain cell survival by inhibiting anoikis (71).

Dihydrodiosgenin inhibits lung metastasis of mouse HCC cells by attenuating the adhesion of cancer cells and platelets to endothelial cells by decreasing FVIII production. The direct antitumor activity may involve the PI3K, MAPK and NF- $\mathrm{BB}$ signaling pathways, which lead to anoikis of HCC cells $(30,31)$.

Additionally, various coagulation-associated factors contribute to anoikis or have anti-anoikis effects in other types of cancer. Coagulation factor IXa was found to attenuate cell adhesion to the matrix and induces anoikis of epidermal cancer cells by increasing MAPK levels (72). Versteeg et al (73) observed that the TF-FVIIa complex enhanced invasion and migration of baby hamster kidney cells via inhibition of anoikis, which was mediated via the PI3K and MAPK signaling pathways.

The liver, unlike other organs, is the main site of coagulation and fibrinolytic factor production. Acquisition of anoikis resistance is a prerequisite for cancer metastasis. In the present review, it was speculated that coagulation- and fibrinolysis-related factors may contribute to intrahepatic metastasis of HCC via resistance to anoikis (Fig. 2).

\section{5. uPA system and immunotherapy for HCC}

Immunotherapy, particularly immune checkpoint therapy targeting programmed death-ligand 1 (PD-L1), cytotoxic T-lymphocyte associated protein 4 (CTLA-4), T-cell immunoglobulin mucin family member 3 (TIM3) and lymphocyte activating 3 (LAG3), serves an important role in tumor treatment. However, most solid tumors only have a $15-30 \%$ effective response rate to immune checkpoint inhibitors (74). Additionally, anti-programmed cell death protein 1 (PD1) therapy has been demonstrated to only have a $14.3 \%$ overall response rate for the treatment of patients with advanced HCC who have been previously treated with sorafenib (75). Studies have suggested that tumor PD-L1 levels may be associated with the response to PD-L1/PD1 blockade $(76,77)$. Previous studies have revealed that low expression levels of PD-L1 in numerous types of HCC could be induced by stimulation of interferon (INF) $-\gamma$, targeted therapies and MYC activation, which decreased antitumor immunity and enhanced HCC progression (78-81).

Nakagawa et al (82) found that major urinary protein (MUP)-uPA mice with high expression levels of uPA specifically 
in the hepatocytes could develop nonalcoholic steatohepatitis-like disease that spontaneously progressed to HCC (82). They suggested that HCC progression in MUP-uPA mice depended on the numbers of immunosuppressive $\operatorname{Ig} \mathrm{A}^{+}$plasma cells. Notably, $\mathrm{IgA}^{+}$plasma cell levels most likely depend on PD-L1 and interleukin (IL)-10 expression (83). This indicated that uPA may be associated with PD-L1 levels in HCC. It would be beneficial to further increase the efficacy of immune checkpoint inhibitors in patients with $\mathrm{HCC}$ if coagulation and fibrinolytic components contribute to the expression of checkpoint molecules.

\section{Summary and outlook}

The majority of patients with tumors present with hypercoagulability, and increasing evidence has demonstrated that the coagulation and fibrinolytic systems are associated with tumor progression. A common characteristic of HCC is intrahepatic metastasis, which leads to a poor prognosis of patients with HCC. Studies have demonstrated that coagulation and fibrinolytic factors may regulate the metastasis of $\mathrm{HCC}$ in two ways. First, by conferring anoikis resistance to HCC cells; second, by promoting $\mathrm{HCC}$ cell escape from immune attacks. In conclusion, it not only protects HCC cells themselves in terms of survival, but also changes the tumor immune microenvironment, both of which eventually lead to intrahepatic metastasis of HCC.

Various treatment methods currently exist for advanced HCC. Molecular targeted therapy and immunotherapy have become popular research topics. However, targeted therapy or immunotherapy only show efficacy in certain patients with HCC, while they have poor efficacy or are even ineffective in the majority of patients. The authors of the present review are currently registering a relevant clinical trial and establishing related animal models, aiming to improve the efficacy of immunotherapy by changing the coagulation and fibrinolysis status of patients with HCC and exploring a specific molecular target, in order to eventually improve the prognosis of patients with HCC.

\section{Acknowledgements}

Not applicable.

\section{Funding}

The present study was supported by the National Natural Science Foundation of China (81670594, 81470791, 81376597); the Basic Research Innovation Group Program of Gansu Province (1606RJIA328); the Scientific Research of Health Services Program of Gansu Province (GSWSKY2017-09); the Talent Staff Fund of the Second Hospital of Lanzhou University (ynyjrckyzx2015-1-01); Talents Innovation and Entrepreneurship Program of Lanzhou City (2017-RC-62); the Cuiying Scientific and Technological Innovation Program of Lanzhou University Second Hospital (CY2017-ZD01); Fundamental Research Funds for the Central Universities (lzujbky-2017-79); Key Project of Science and Technology in Gansu Province (19ZD2WA001).

\section{Availability of data and materials}

All information included in this Review is documented by relevant and current references.

\section{Authors' contributions}

$\mathrm{XL}, \mathrm{BG}$ and $\mathrm{BW}$ wrote the manuscript; XL, AL and $\mathrm{HC}$ designed the paper; ZF, YM and HL revised the manuscript. All authors read and approved the final manuscript and agreed to be accountable for all aspects of the work in ensuring that questions related to the accuracy or integrity of any part of the work are appropriately investigated and resolved.

\section{Ethics approval and consent to participate}

Not applicable.

\section{Patient consent for publication}

Not applicable.

\section{Competing interests}

The authors declare that they have no competing interests.

\section{References}

1. Siegel RL, Miller KD and Jemal A: Cancer statistics, 2019. CA Cancer J Clin 69: 7-34, 2019.

2. Villanueva A: Hepatocellular carcinoma. N Engl J Med 380: $1450-1462,2019$.

3. Kulik L and El-Serag HB: Epidemiology and management of hepatocellular carcinoma. Gastroenterology 56: 477-491, 2019.

4. Miller KD, Nogueira L, Mariotto AB, Rowland JH, Yabroff KR, Alfano CM, Jemal A, Kramer JL and Siegel RL: Cancer treatment and survivorship statistics, 2019. CA Cancer J Clin 69: 363-385, 2019.

5. Roayaie S, Jibara G, Tabrizian P, Park JW, Yang J, Yan L, Schwartz M, Han G, Izzo F, Chen M, et al: The role of hepatic resection in the treatment of hepatocellular cancer. Hepatology 62: 440-451, 2015.

6. Tabrizian P, Jibara G, Shrager B, Schwartz M and Roayaie S: Recurrence of hepatocellular cancer after resection: Patterns, treatments, and prognosis. Ann Surg 261: 947-955, 2015.

7. Kanoh Y: Coagulation and fibrinolytic system. Nihon Rinsho 74 (Suppl 4): S301-S305, 2016 (In Japanese).

8. Tsai MC, Yen YH, Chang KC, Hung CH, Chen $\mathrm{CH}$, Lin MT and $\mathrm{Hu} \mathrm{TH}$ : Elevated levels of serum urokinase plasminogen activator predicts poor prognosis in hepatocellular carcinoma after resection. BMC Cancer 19: 1169, 2019.

9. Wei L, Lun Y, Zhou X, He S, Gao L, Liu Y, He Z, Li B and Wang C: Novel urokinase-plasminogen activator inhibitor SPINK13 inhibits growth and metastasis of hepatocellular carcinoma in vivo. Pharmacol Res 143: 73-85, 2019.

10. Zacharski LR: Anticoagulants in cancer treatment: Malignancy as a solid phase coagulopathy. Cancer Lett 186: 1-9, 2002.

11. Lip GY, Chin BS and Blann AD: Cancer and the prothrombotic state. Lancet Oncol 3: 27-34, 2002.

12. Zacharski LR, Wojtukiewicz MZ, Costantini V, Ornstein DL and Memoli VA: Pathways of coagulation/fibrinolysis activation in malignancy. Semin Thromb Hemost 18: 104-116, 1992.

13. Falanga A, Marchetti M and Vignoli A: Coagulation and cancer: Biological and clinical aspects. J Thromb Haemost 11: 223-233, 2013.

14. Thodiyil PA and Kakkar AK: Variation in relative risk of venous thromboembolism in different cancers. Thromb Haemost 87: 1076-1077, 2002.

15. Nadir Y: Decreasing tumor growth and angiogenesis by inhibition of coagulation. Semin Thromb Hemost 45: 622-628, 2019.

16. Sun H, Cao D, Liu Y, Wang H, Ke X and Ci T: Low molecular weight heparin-based reduction-sensitive nanoparticles for antitumor and anti-metastasis of orthotopic breast cancer. Biomater Sci 6: 2172-2188, 2018.

17. Furie B and Furie BC: The molecular basis of blood coagulation. Cell 53: 505-518, 1988. 
18. Zhou Q, Huang T, Wang YF, Zhou XB, Liang LJ and Peng BG: Role of tissue factor in hepatocellular carcinoma genesis, invasion and metastasis. Chin Med J (Engl) 124: 3746-3751, 2011.

19. Huang SZ, Wei MN, Huang JR, Zhang ZJ, Zhang WJ, Jiang QW, Yang Y, Wang HY, Jin HL, Wang K, et al: Targeting TF-AKT/ ERK-EGFR pathway suppresses the growth of hepatocellular carcinoma. Front Oncol 9: 150, 2019.

20. Dupuy E, Hainaud $P$, Villemain A, Bodevin-Phèdre E, Brouland JP, Briand P and Tobelem G: Tumoral angiogenesis and tissue factor expression during hepatocellular carcinoma progression in a transgenic mouse model. J Hepatol 38: 793-802, 2003.

21. Poon RT, Lau CP, Ho JW, Yu WC, Fan ST and Wong J: Tissue factor expression correlates with tumor angiogenesis and invasiveness in human hepatocellular carcinoma. Clin Cancer Res 9: 5339-5345, 2003.

22. Panasiuk A, Zak J, Panasiuk B and Prokopowicz D: Increase in expression of monocytic tissue factor (CD142) with monocytes and blood platelet activation in liver cirrhosis. Blood Coagul Fibrinolysis 18: 739-744, 2007

23. Tian M, Wan Y, Tang J, Li H, Yu G, Zhu J, Ji S, Guo H, Zhang N, $\mathrm{Li}$ W, et al: Depletion of tissue factor suppresses hepatic metastasis and tumor growth in colorectal cancer via the downregulation of MMPs and the induction of autophagy and apoptosis. Cancer Biol Ther 12: 896-907, 2011.

24. Li H, Tian ML, Yu G, Liu YC, Wang X, Zhang J, Ji SQ, Zhu J, Wan YL and Tang JQ: Hyperthermia synergizes with tissue factor knockdown to suppress the growth and hepatic metastasis of colorectal cancer in orthotopic tumor model. J Surg Oncol 106: 689-695, 2012

25. Zerbib P, Grimonprez A, Corseaux D, Mouquet F, Nunes B, Petersen LC, Susen S, Ung A, Hebbar M, Pruvot FR, et al: Inhibition of tissue factor-factor VIIa proteolytic activity blunts hepatic metastasis in colorectal cancer. J Surg Res 153: 239-245, 2009.

26. Neaud V, Hisaka T, Monvoisin A, Bedin C, Balabaud C, Foster DC, Desmoulière A, Kisiel W and Rosenbaum J: Paradoxical pro-invasive effect of the serine proteinase inhibitor tissue factor pathway inhibitor-2 on human hepatocellular carcinoma cells. J Biol Chem 275: 35565-35569, 2000.

27. Tsai MC, Chen KD, Wang CC, Huang KT, Wu CH, Kuo IY, Chen LY, Hu TH, Goto S, Nakano T, et al: Factor VII promotes hepatocellular carcinoma progression through ERK-TSC signaling. Cell Death Discov 1: 15051, 2015.

28. Chen KD, Wang CC, Tsai MC, Wu CH, Yang HJ, Chen LY, Nakano T, Goto S, Huang KT, Hu TH, et al: Interconnections between autophagy and the coagulation cascade in hepatocellular carcinoma. Cell Death Dis 5: e1244, 2014.

29. Lin $\mathrm{CC}, \mathrm{Wu} \mathrm{CH}$, Chen LY, Tsai MC, Elsarawy AM and Huang KT: Coagulation factor VII gene polymorphisms are not associated with the occurrence or the survival of hepatocellular carcinoma: A report of 37 cases. Cancer Biol Med 15: 275-281, 2018.

30. Li Y, Wang X, Cheng S, Du J, Deng Z, Zhang Y, Liu Q, Gao J, Cheng B and Ling C: Diosgenin induces G2/M cell cycle arrest and apoptosis in human hepatocellular carcinoma cells. Oncol Rep 33: 693-698, 2015.

31. Zhuang M, Xin G, Wei Z, Li S, Xing Z, Ji C, Du J, Niu H and Huang W: Dihydrodiosgenin inhibits endothelial cell-derived factor VIII and platelet-mediated hepatocellular carcinoma metastasis. Cancer Manag Res 11: 4871-4882, 2019.

32. Yoo BK, Chen D, Su ZZ, Gredler R, Yoo J, Shah K, Fisher PB and Sarkar D: Molecular mechanism of chemoresistance by astrocyte elevated gene-1. Cancer Res 70: 3249-3258, 2010.

33. Srivastava J, Siddiq A, Emdad L, Santhekadur PK, Chen D, Gredler R, Shen XN, Robertson CL, Dumur CI, Hylemon PB, et al: Astrocyte elevated gene-1 promotes hepatocarcinogenesis: Novel insights from a mouse model Hepatology 56: 1782-1791, 2012.

34. Dan $\varnothing \mathrm{K}$, Andreasen PA, Grøndahl-Hansen J, Kristensen P, Nielsen LS and Skriver L: Plasminogen activators, tissue degradation, and cancer. Adv Cancer Res 44: 139-266, 1985.

35. Liotta LA, Tryggvason K, Garbisa S, Hart I, Foltz CM and Shafie S: Metastatic potential correlates with enzymatic degradation of basement membrane collagen. Nature 284: 67-68, 1980.

36. Sun BS, Dong QZ, Ye QH, Sun HJ, Jia HL, Zhu XQ, Liu DY, Chen J, Xue Q, Zhou HJ, et al: Lentiviral-mediated miRNA against osteopontin suppresses tumor growth and metastasis of human hepatocellular carcinoma. Hepatology 48: 1834-1842, 2008 .
37. Cao X, Zhang L, Shi Y, Sun Y, Dai S, Guo C, Zhu F, Wang Q, Wang J, Wang X, et al: Human tumor necrosis factor (TNF)-alpha-induced protein 8-like 2 suppresses hepatocellular carcinoma metastasis through inhibiting Rac1. Mol Cancer 12: 149,2013

38. Tsai JP, Hsiao PC, Yang SF, Hsieh SC, Bau DT, Ling CL, Pai CL and Hsieh YH: Licochalcone a suppresses migration and invasion of human hepatocellular carcinoma cells through downregulation of MKK4/JNK via NF- $\kappa \mathrm{B}$ mediated urokinase plasminogen activator expression. PLoS One 9: e86537, 2014.

39. Weng CJ, Chou CP, Ho CT and Yen GC: Molecular mechanism inhibiting human hepatocarcinoma cell invasion by 6 -shogaol and 6-gingerol. Mol Nutr Food Res 56: 1304-1314, 2012.

40. Lee KH, Choi EY, Hyun MS, Jang BI, Kim TN, Lee HJ, Eun JY, Kim HG, Yoon SS, Lee DS, et al: Role of hepatocyte growth factor/c-Met signaling in regulating urokinase plasminogen activator on invasiveness in human hepatocellular carcinoma: A potential therapeutic target. Clin Exp Metastasis 25: 89-96, 2008.

41. Sun H and Liu GT: Inhibitory effect of anti-hepatitis drug bicyclol on invasion of human hepatocellular carcinoma MHCC 97-H cells with high metastasis potential and its relative mechanisms. J Asian Nat Prod Res 11: 576-583, 2009.

42. Blasi F and Carmeliet P: uPAR: A versatile signalling orchestrator. Nat Rev Mol Cell Biol 3: 932-943, 2002.

43. Sakakibara T, Hibi K, Koike M, Fujiwara M, Kodera Y, Ito K and Nakao A: Plasminogen activator inhibitor-1 as a potential marker for the malignancy of colorectal cancer. Br J Cancer 93: 799-803, 2005.

44. Zhou L, Jin Y, Cui QC, Jin KM, Zhou WX and Xing BC: Low expression of PAI-2 as a novel marker of portal vein tumor thrombosis and poor prognosis in hepatocellular carcinoma. World J Surg 37: 608-613, 2013.

45. Weng CJ, Tsai CM, Chen YC, Hsieh YH, Lin CW, Liu YF, Su SC, Chen MK and Yang SF: Evaluation of the association of urokinase plasminogen activator system gene polymorphisms with susceptibility and pathological development of hepatocellular carcinoma. Ann Surg Oncol 17: 3394-3401, 2010.

46. Chen H, Peng H, Liu W, Sun Y, Su N, Tang W, Zhang X, Wang J, Cui L, Hu P, et al: Silencing of plasminogen activator inhibitor-1 suppresses colorectal cancer progression and liver metastasis. Surgery 158: 1704-1713, 2015.

47. Divella R, Daniele A, Abbate I, Savino E, Casamassima P, Sciortino G, Simone G, Gadaleta-Caldarola G, Fazio V, Gadaleta CD, et al: Circulating levels of PAI-1 and SERPINE1 $4 \mathrm{G} / 4 \mathrm{G}$ polymorphism are predictive of poor prognosis in $\mathrm{HCC}$ patients undergoing TACE. Transl Oncol 8: 273-278, 2015.

48. Wang X, Wang N, Li H, Liu M, Cao F, Yu X, Zhang J, Tan Y, Xiang L and Feng Y: Up-Regulation of PAI-1 and down-regulation of $\mathrm{UPA}$ are involved in suppression of invasiveness and motility of hepatocellular carcinoma cells by a natural compound berberine. Int J Mol Sci 17: 577, 2016.

49. Jin Y, Liang ZY, Zhou WX and Zhou L: Plasminogen activator inhibitor 2 (PAI2) inhibits invasive potential of hepatocellular carcinoma cells in vitro via uPA- and RB/E2F1-related mechanisms. Hepatol Int 13: 180-189, 2019.

50. Pang RW, Joh JW, Johnson PJ, Monden M, Pawlik TM and Poon RT: Biology of hepatocellular carcinoma. Ann Surg Oncol 15: 962-971,2008.

51. Kudo A, Shinoda M, Ariizumi S, Kumamoto T, Katayama M, Otsubo T, Endo I, Kitagawa Y, Tanabe Y, Yamamoto M, et al: Des-gamma-carboxy prothrombin affects the survival of HCC patients with marginal liver function and curative treatment: ACRoS1402. J Cancer Res Clin Oncol.2020 (Epub ahead of print).

52. Li Y and Chen J: Serum des-gamma-carboxy prothrombin for diagnosis of adult primary cancer in liver. J Coll Physicians Surg Pak 29: 972-976, 2019.

53. Cai Z, Chen G, Zeng Y, Dong X, Li Z, Huang Y, Xin F, Qiu L, $\mathrm{Xu} \mathrm{H}$, Zhang W, et al: Comprehensive liquid profiling of circulating tumor DNA and protein biomarkers in long-term follow-up patients with hepatocellular carcinoma. Clin Cancer Res 25: 5284-5294, 2019

54. Tang W, Miki K, KokudoN, Sugawara Y,Imamura H,Minagawa M, Yuan LW, Ohnishi S and Makuuchi M: Des-gamma-carboxy prothrombin in cancer and non-cancer liver tissue of patients with hepatocellular carcinoma. Int J Oncol 22: 969-975, 2003.

55. SuzukiM, Shiraha H,Fujikawa T, Takaoka N, Ueda N, Nakanishi Y, Koike K, Takaki A and Shiratori Y: Des-gamma-carboxy prothrombin is a potential autologous growth factor for hepatocellular carcinoma. J Biol Chem 280: 6409-6415, 2005. 
56. Gao FJ, Cui SX, Chen MH, Cheng YN, Sun LR, Ward SG, Kokudo N, Tang W and Qu XJ: Des-gamma-carboxy prothrombin increases the expression of angiogenic factors in human hepatocellular carcinoma cells. Life Sci 83: 815-820, 2008.

57. Yue P, Gao ZH, Xue X, Cui SX, Zhao CR, Yuan Y, Yin Z Inagaki Y, Kokudo N, Tang W and Qu XJ: Des- $\gamma$-carboxyl prothrombin induces matrix metalloproteinase activity in hepatocellular carcinoma cells by involving the ERK1/2 MAPK signalling pathway. Eur J Cancer 47: 1115-1124, 2011.

58. Murata $\mathrm{K}$ and Sakamoto A: Impairment of clathrin-mediated endocytosis via cytoskeletal change by epithelial to fibroblastoid conversion in HepG2 cells: A possible mechanism of des-gamma-carboxy prothrombin production in hepatocellular carcinoma. Int J Oncol 33: 1149-1155, 2008.

59. Murata K, Suzuki H, Okano H, Oyamada T, Yasuda Y and Sakamoto A: Hypoxia-induced des-gamma-carboxy prothrombin production in hepatocellular carcinoma. Int J Oncol 36: 161-170, 2010.

60. Mizuta T, Ozaki I, Eguchi Y, Yasutake T, Kawazoe S, Fujimoto K and Yamamoto K: The effect of menatetrenone, a vitamin K2 analog, on disease recurrence and survival in patients with hepatocellular carcinoma after curative treatment: A pilot study. Cancer 106: 867-872,2006.

61. Otsuka M, Kato N, Shao RX, Hoshida Y, Ijichi H, Koike Y, Taniguchi H, Moriyama M, Shiratori Y, Kawabe T and Omata M: Vitamin K2 inhibits the growth and invasiveness of hepatocellular carcinoma cells via protein kinase A activation. Hepatology 40: 243-251, 2004.

62. Shi CS, Shi GY, Hsiao HM, Kao YC, Kuo KL, Ma CY, Kuo CH Chang BI, Chang CF, Lin CH, et al: Lectin-like domain of thrombomodulin binds to its specific ligand Lewis Y antigen and neutralizes lipopolysaccharide-induced inflammatory response. Blood 112: 3661-3670, 2008.

63. Suehiro T, Shimada M, Matsumata T, Taketomi A, Yamamoto K and Sugimachi K: Thrombomodulin inhibits intrahepatic spread in human hepatocellular carcinoma. Hepatology 21: 1285-1290, 1995.

64. Huang MT, Wei PL, Liu JJ, Liu DZ, Huey-Chun H, An J, Wu CC, Wu CH, Ho YS, Yang YY and Chang YJ: Knockdown of thrombomodulin enhances HCC cell migration through increase of ZEB1 and decrease of E-cadherin gene expression. Ann Surg Oncol 17: 3379-3385, 2010

65. Hasegawa M, Nakoshi Y, Iino T, Sudo A, Segawa T, Maeda M, Yoshida T and Uchida A: Thrombin-cleaved osteopontin in synovial fluid of subjects with rheumatoid arthritis. J Rheumatol 36: 240-245, 2009

66. Xue YH, Zhang XF, Dong QZ, Sun J, Dai C, Zhou HJ, Ren N, Jia HL, Ye QH and Qin LX: Thrombin is a therapeutic target for metastatic osteopontin-positive hepatocellular carcinoma. Hepatology 52: 2012-2022, 2010.

67. Liotta LA and Kohn E: Anoikis: Cancer and the homeless cell Nature 430: 973-974, 2004

68. Kim YN, Koo KH, Sung JY, Yun UJ and Kim H: Anoikis resistance: An essential prerequisite for tumor metastasis. Int J Cell Biol 2012: 306879, 2012.

69. Frisch SM and Francis H: Disruption of epithelial cell-matrix interactions induces apoptosis. J Cell Biol 124: 619-626, 1994.
70. Zhang X, Cheng SL, Bian K, Wang L, Zhang X, Yan B, Jia LT, Zhao J, Gammoh N, Yang AG and Zhang R: MicroRNA-26a promotes anoikis in human hepatocellular carcinoma cells by targeting alpha5 integrin. Oncotarget 6: 2277-2289, 2015.

71. Jia Q, Xue T, Zhang Q, Cheng W, Zhang C, Ma J, Bu Y, Yu S and Liu Q: CCN3 is a therapeutic target relating enhanced stemness and coagulation in hepatocellular carcinoma. Sci Rep 7: 13846, 2017.

72. Ishikawa T, Kitano H, Mamiya A, Kokubun S and Hidai C: The first EGF domain of coagulation factor IX attenuates cell adhesion and induces apoptosis. Biosci Rep 36: e00340, 2016.

73. Versteeg HH, Spek CA, Richel DJ and Peppelenbosch MP: Coagulation factors VIIa and $\mathrm{Xa}$ inhibit apoptosis and anoikis. Oncogene 23: 410-417, 2004.

74. Das S and Johnson DB: Immune-related adverse events and anti-tumor efficacy of immune checkpoint inhibitors. J Immunother Cancer 7: 306, 2019.

75. El-Khoueiry AB, Sangro B, Yau T, Crocenzi TS, Kudo M, Hsu C, Kim TY, Choo SP, Trojan J, Welling TH Rd, et al: Nivolumab in patients with advanced hepatocellular carcinoma (CheckMate 040): An open-label, non-comparative, phase $1 / 2$ dose escalation and expansion trial. Lancet 389: 2492-2502, 2017.

76. Herbst RS, Soria JC, Kowanetz M, Fine GD, Hamid O, Gordon MS, Sosman JA, McDermott DF, Powderly JD, Gettinger SN, et al: Predictive correlates of response to the anti-PD-L1 antibody MPDL3280A in cancer patients. Nature 515: 563-567, 2014.

77. Zhang J, Bu X, Wang H, Zhu Y, Geng Y, Nihira NT, Tan Y, Ci Y, Wu F, Dai X, et al: Cyclin D-CDK4 kinase destabilizes PD-L1 via cullin 3-SPOP to control cancer immune surveillance. Nature 553: 91-95, 2018

78. Casey SC, Tong L, Li Y, Do R, Walz S, Fitzgerald KN, Gouw AM, Baylot V, Gütgemann I, Eilers M and Felsher DW: MYC regulates the antitumor immune response through CD47 and PD-L1. Science 352: 227-231, 2016

79. Li N, Wang J, Zhang N, Zhuang M, Zong Z, Zou J, Li G, Wang X, Zhou H, Zhang L and Shi Y: Cross-talk between TNF- $\alpha$ and IFN- $\gamma$ signaling in induction of B7-H1 expression in hepatocellular carcinoma cells. Cancer Immunol Immunother 67: 271-283, 2018.

80. Xiang J, Zhang N, Sun H, Su L, Zhang C, Xu H, Feng J, Wang M, Chen J, Liu L, et al: Disruption of SIRT7 increases the efficacy of checkpoint inhibitor via MEF2D regulation of programmed cell Death 1 Ligand 1 in hepatocellular carcinoma cells. Gastroenterology 158: 664-678.e24, 2020.

81. Zhou J, Liu M, Sun H, Feng Y, Xu L, Chan AWH, Tong JH, Wong J, Chong CCN, Lai PBS, et al: Hepatoma-intrinsic CCRK inhibition diminishes myeloid-derived suppressor cell immunosuppression and enhances immune-checkpoint blockade efficacy. Gut 67: 931-944, 2018.

82. Nakagawa H, Umemura A, Taniguchi K, Font-Burgada J, Dhar D, Ogata H, Zhong Z, Valasek MA, Seki E, Hidalgo J, et al: ER stress cooperates with hypernutrition to trigger TNF-dependent spontaneous HCC development. Cancer Cell 26: 331-343, 2014.

83. Febbraio MA, Reibe S, Shalapour S, Ooi GJ, Watt MJ and Karin M: Preclinical models for studying NASH-Driven HCC: How useful are they? Cell Metab 29: 18-26, 2019. 